\title{
Towards Integrated Traveller Information
}

\author{
GLENN D. LYONS
}

Transportation Research Group, Department of Civil and Environmental Engineering, University of Southampton, Highfield, Southampton SO17 1BJ, UK

\section{Abstract}

Traveller information provision has become a key Government priority in the UK following the publication of its Transport White Paper in July 1998. Developments are already underway for the integration of information systems across different public transport modes and between public transport information systems covering different regions. The Highways Agency (which is responsible for managing the strategic road network in the UK) is also advancing in its development of information databases and systems for the motorist. This paper considers the prospect of providing travellers with multimodal information with integration of driver information with public transport information. If such integration can be achieved then travellers, and in particular drivers, have the prospect of being presented with comparable information on travel options across modes. An integrated information service has great potential to inform and influence travel choices. The paper considers the issue of travel choices and the role that information can play particularly in the context of mode choice. The political (UK) and technological climate for information provision is outlined. The paper identifies a number of issues that will need to be addressed to identify the requirements from, and potential benefits of, integrated information and the obstacles and challenges that are likely to be faced in moving towards it. Driver reactions, in particular, to the prospect of integrated information provision are fundamental to the assessment of its potential importance and value. 


\section{Introduction}

Figure 1 highlights an all too familiar trend in the UK and other developed countries. The car has presented society with a highly flexible, reliable, convenient, comfortable and cheap form of transport providing enhanced mobility and accessibility to millions of people. As dependence on the car has grown, the collective (relative) dependence on public transport has declined. With falling levels of patronage on bus services and the national press and public critical of service reliability of the privatised passenger rail industry, society has acquired an unfavourable view of public transport as depicted by table 1 .

\section{Insert figure 1 about here}

\section{Insert table 1 about here}

UK transport policy had, until recently, adopted a 'predict and provide' approach to address burgeoning levels of car-based travel demand. Predicted future levels of traffic were determined and then additional highway capacity was provided to accommodate it. In the late 1990s a profound U-turn in policy took place. The SACTRA report (1994) brought about recognition and acceptance that building new roads could generate (some) new traffic. In addition to the huge cost implications of new road construction it was realised that additional capacity could only provide a temporary reprieve from growing levels of congestion and increasingly long and unreliable journey times on the highway network. The Conservative Government launched a national transport debate and towards the end of its term of office produced a Transport Green Paper (DOT 1996). The current Labour Government progressed this. Further consultation culminated in publication of the first Transport White Paper in the UK for some 20 years setting out a new agenda for transport policy (DETR 1998a). 
The White Paper introduced a much greater emphasis on managing the demand for (car-based) travel rather than only attempting to accommodate and manage the traffic on the highway network. Central to the aims of the White Paper is the need to reduce society's dependence on the motor car. New initiatives are concerned with making alternative modes of travel to the car more attractive and viable and with reducing the need to travel. A renaissance in public transport is being encouraged. Motorists are likely to become subject increasingly to the persuasion of economic instruments and commuter and business traffic has become the target of green transport plans.

The White Paper makes over 100 references to information. Information can improve public transport journeys by making it easier for travellers to plan and execute trips. Information can inform travellers of the alternatives for making a trip. The latter is particularly important as public transport services begin to improve. Many car drivers are unaware of public transport alternatives or are ill-informed about the merits of such alternatives. Better provision of information to travellers can, if viable alternatives to the car exist, promote a more sustainable distribution of trips across modes. The key theme of the White Paper is integration. Integration has a number of aspects but one in particular is the 'integration within and between different types of transport - so that each contributes its full potential and people can move easily between them' (DETR 1998a). Provision of traveller information supports this.

There is considerable emphasis in the UK on developing (better) public transport information systems. There is also a need to consider driver information systems and ultimately to address the prospect of integrating information across modes. This would potentially provide a convenient means for travellers to make (more) fully informed decisions based on comparative information across modes. 
The Highways Agency (HA) in the UK was established in 1994 and is an executive agency of the Department of Environment, Transport and the Regions (DETR). The HA's aim is to contribute to sustainable development by maintaining, operating and improving the UK's strategic road network in support of the Government's integrated transport and land use planning. As a consequence of the transition in UK transport policy the HA has seen its role transform from one of network builder to network operator. At the end of the 1990s it became very proactive in responding to this new role and established a major stream of investment into shortterm and longer-term research. The latter is being addressed by its Outward Facing Research Programme. One element of the Programme concerns integration and specifically the integration of information systems across modes. Research has recently been commissioned to investigate this area. This paper stems from the preliminary investigation of research needs (the 'desk study'). The author also provides an assessment of the potential progression towards integrated traveller information systems. The paper considers the role that information can play in informing and influencing choice. It outlines the issues that must be addressed not simply to technically provide integrated information but to determine whether and how such systems can perform effectively and deliver positive benefits. Figure 2 offers one perspective on future developments.

\section{Insert figure 2 about here}

\section{Making informed choices}

\subsection{What Choices?}

The travel choices faced by individuals are many. There is perhaps an inclination to focus attention on short-term decisions associated with individual trips. The first short-term choice is whether or not a trip is needed. A trip is made to 
participate in an activity and the trip itself is a means to an end and something individuals would, out of preference, avoid (or at least this is the assumption in choice theory). Individuals may be able to participate in activities without making trips or by making fewer trips. Teleservices such as teleshopping and teleworking do not require a physical trip. More efficient scheduling of activities could reduce the number of trips.

If the decision has been made to make a trip, the remaining choices concern when and how the transport system is used. Some of these choices will be subject to constraints. For example, the times, dates and venues of the activities might be fixed. The mode of travel options might be constrained if the person does not own a car. The collective short-term choices that are made determine how well the spatial and temporal capacities of the available transport networks and services are used.

Although individuals face all of these short terms choices for each trip considered, they may not review all the choices each time they make a trip. For example, it is unlikely that many people review the service or route for their commute trip every day or even every month. Further still, how many people review the mode choices for every trip, particularly a trip that has been made before?

Long-term choices could have a much more profound influence on society's travel patterns than short-term choices. Human beings are creatures of habit and happily settle into routine patterns of behaviour, including those for travel. The merits of alternative choice options for a particular trip may change but individuals may only assess these options on one occasion and then for all subsequent occasions assume their previous decisions remain valid.

The relative merits of short-term choices can be influenced by long-term choices. When an individual reviews his or her commute trip options, for example, he 
or she may be faced with a choice between an initial outlay on buying a new car or on purchasing a public transport season ticket or saver card. Deciding where to live and work determines trip lengths and the availability of viable travel options, particularly concerning mode of travel.

\subsection{How Are Choices Made?}

In making a trip, an individual incurs a number of elements of 'cost' such as monetary cost, travel time, (dis)comfort, (in)convenience and (un)reliability. Collectively these are referred to as generalised travel cost (Ortúzar and Willumsen 1994, IHT 1997). Monetary cost and travel time are tangible and measurable and often assumed to be primary costs. Each individual will perceive and weigh cost elements differently depending on the characteristics of the individual and the circumstances in which the trip or trips is/are being made. Theory assumes that an individual will seek to minimise cost when considering alternative travel options.

Figure 3 shows the response of users of an Internet-based traveller information service when asked to rank the five elements of cost mentioned above. The sample may or may not be representative of the population as a whole but the response highlights that convenience, reliability and comfort are important determinants of cost. In this example over $60 \%$ of respondents rated convenience, reliability or comfort more highly than cost or time.

\section{Insert figure 3 about here}

While time and cost can be readily quantified, convenience, reliability and comfort cannot. During focus group sessions conducted with travellers (Board et al. 1999) it was suggested that statistical information concerning reliability could be included when traveller information is provided. For example 'the train is scheduled to depart at $12.05 \mathrm{pm}$ and has been within two minutes of this time for $98 \%$ of service 
runs during the last three months'. Monetary cost is influenced by an individual's means to pay (income) or indeed by who pays. If it is a business trip then monetary cost may be, within reason, ignored by the individual and other cost factors considered more closely. For a business trip the importance of reliability in arriving at a meeting on time may outweigh the need to minimise travel time. Travelling by car may be more convenient if accompanied by children or luggage. Likewise travelling by car may be more comfortable and less stressful than sharing a crowded public transport carriage with other people.

The array of choices and factors that are used to judge the relative merits of alternatives paints a complex picture to address in terms of influencing travel patterns. With regard to mode choice, if public transport can surpass the car in all cost elements then people may leave their cars. The unfortunate reality (or perceived reality) in many cases is the reverse which is frequently reinforced by the longer term choices mentioned earlier.

\subsection{How Can Choices Be Influenced?}

Changing the relative costs of the alternatives available should influence choice. The Transport White Paper is very much concerned with reducing the cost of public transport with improved travel times using bus priority measures, increased reliability and improved convenience with a series of initiatives to make public transport journeys more seamless. Concurrent with steps to improve public transport is the use of economic instruments that seek to increase the cost of car travel with ongoing fuel cost increases and parking charges.

Since perceptions of cost almost certainly favour the car at present, at the very least the actual cost of public transport must change to be no more than that by car. Monetary cost remains a problem in this regard with the fixed costs of motoring 
forcing a perceived low per-trip variable cost when compared to the public transport alternatives where the full cost is paid at point of use. If an individual has a company car then the situation is even worse. Public transport cannot compete on a level playing field because the fixed costs and potentially the running costs of the car are not met by the individual.

Beyond the reality of actual cost is the matter of perceived cost. If there is a mismatch between perceived and actual cost then sub-optimal choices may be made by individuals. In some cases this will result in the use of the car when public transport would have been 'cheaper'.

Perceptions of cost can be influenced by past experience. Reliability is something which is, in particular, assessed based on previous occasions when a particular trip was made or when a particular mode was used. It is difficult to gauge reliability without past experience. The route taken on a commute trip is based on or reinforced by past experience. If an individual makes a trip on one or two occasions and judges from this the best way to make that trip again in future, he or she may be unlikely to review certain choices for this trip again - even if the actual costs of the alternatives are changed over time.

Bad experiences are recalled more readily than satisfactory or good experiences and hence bad experiences can more readily shape perceptions. Indeed experiences are prone to become coloured by time. In a report on house-buying it was noted that:

' Bad experiences with buying and selling a property are often good "dinner table gossip". There might be a tendency to exaggerate events, especially if others have had a similar experience.' (DETR 1999b). 
Past experiences of other people can strongly influence choices and can propagate very quickly through informal community information networks. In some cases past-experiences of others may be well-informed however in other cases such experience will not constitute reliable, fully-informed information and could serve to (further) distort perceptions of cost.

To more effectively influence choices the individual needs to be presented with reliable, comprehensive information concerning the alternatives upon which to base a decision. This signals a cue for traveller information systems which should in principle offer accurate and unbiased information relating to the alternative choices available. By presenting comparable information across modes traveller information systems have the potential to ensure that travellers make well informed choices with the implicit hope in particular that in so doing drivers will, in some instances, elect to use an alternative mode.

Information cannot change the 'disutility' (generalised cost) of a particular mode for a particular journey. It can only change the perception of disutility. There will be many occasions when the provision of integrated information would simply serve to highlight the disparity between a trip by private transport as opposed to public transport and reinforce a decision to travel by car. However, as the White Paper policies emerge and take effect, relative actual costs of alternatives should change and it will then be important that travellers can have facilities to easily review their choices to take account of such change.

\section{Traveller information systems}

Information is an integral part of a transport service and as such it contributes to the overall quality of the service. Road signing assures drivers at regular intervals 
of the direction in which they are heading and how far they have to go to reach key points along their journey and their destination. Passenger information can make a multi-stage public transport journey appear more seamless by making it easier for the traveller to execute the journey. By offering reassurance and making it easier to travel, information may encourage more use of a service. Real-time information can help in accommodating the unreliability of a transport service by providing the traveller enroute with the option to revise choices to make best use of the service or available alternative(s).

Journey planners enable travellers to determine how to reach their destination and to obtain an itinerary for how to complete the selected journey (see figure 4). For unfamiliar trips this is particularly important.

\section{Insert figure 4 about here}

Perhaps the greatest expectation is that traveller information can inform and influence choice. It can redress misconceptions of cost and might also alert the recipient to travel options that had hitherto not been considered.

Traveller information is not a new concept. Paper timetables and road maps have been in use for many years but today attention tends to focus on Advanced Traveller Information Systems (ATIS) - systems which are sophisticated and which capitalise and depend upon the latest technologies to deliver information. The interpretation of the term 'advanced' should be treated with care. 'Advanced' in its true sense should mean a system that fully serves its purpose - i.e. to effectively inform the traveller.

Ultimately for an information system to be effective it must be able to address user needs. It must present information in a form that is both comprehensive and comprehendable. The information must be appropriate. User requirements will vary 
according to the characteristics of different users and will be influenced by the types of journeys being made (Gillam et al. 1999).

\subsection{Access to information}

There are now a number of mechanisms to deliver and receive information. Two key communications media are the Internet and telephone.

The Internet and in particular the World Wide Web (Web) has rapidly developed from being a plaything for academics to becoming a mainstream communications medium offering substantial flexibility and versatility in information exchange. Growth in Internet use globally has been prolific with an estimated increase in the number of computers connected to the Internet of $1750 \%$ over the last five years and a growth of over 50\% during the last year (see figure 5). The 1999 Which? Annual Internet Survey (see http://www.which.net/) estimated that approximately 14\% of Britons were using the Internet. More recent survey results suggest that at the end of 1999 this figure was closer to 20\% (Internet Magazine 1999). The growth in household access is being spurred on by attractive Internet connection packages from Internet Service Providers (ISPs). During the coming decades most, if not all, homes will have access to the Internet (not necessarily via a PC but perhaps via digital TV, games consoles, telephones, etc.).

\section{Insert figure 5 about here}

As the number of people with access to the Internet has grown, so too has the number of Web sites providing traveller information. There are currently some 400 sites in the UK that provide public transport information ranging from basic contact details for local bus operators through regional or mode specific journey planning facilities to real-time bus and train information (Austin 1999). Sites relating to driver information are also available offering such things as route planning facilities, information on incidents and journey times. 
$94 \%$ of UK households have a telephone. It is estimated that $41 \%$ of the population have mobile phones and the number of handsets now outnumbers the 23.8 million residential fixed lines installed nationwide (McIntosh, 2000). The telephone now provides access to information irrespective of user location. Mobile communications technology is leading to an advance from 'mere' telephone handsets to more versatile communications devices or 'Personal Digital Assistants' with the ability to access the Internet (see figure 6) and capability of global positioning.

\section{Insert figure 6 about here}

It is evident that travellers have increasingly the means to access information both pre-trip and enroute, irrespective of their location. As accessibility to information increases the tendency to wish to seek information will become more habitual and hence demand for travel information is likely to increase. Through experience of obtaining timely and reliable travel information, future levels of use of such information will increase (Harris and Konheim 1995 (Polydoropoulou et al. 1994). In the UK, use of the National Rail (telephone) Enquiry Service (NRES) has increased from 37 million calls in its first year of operation in 1997 to 60 million calls in 1999 (ATOC 1999). Use of the Railtrack Web site (http://www.railtrack.co.uk/travel/) which provides timetable-based planning for national rail journeys has increased over the same period and now handles over 60 million journey planner enquiries per year. In terms of information management and dissemination, inter-connectivity and interrogation between travel information databases (via the Internet) is likely to become commonplace with established protocols and procedures.

It is difficult to fully conceive the technological advances that will take place in the next 20 years or indeed the next 5 years. Such advances and the opportunities for information exchange they provide are extensive. It can be surmised that 
technological issues are unlikely, in themselves, to present impediments to the exchange of information whether in terms of the capabilities of, cost of or access to telecommunications technology. Information and communications technology now provides the opportunity to acquire, exchange and manage data from multiple sources thereby enabling the production of integrated traveller information systems covering more than one mode or geographical region.

The extent to which provision of integrated traveller information can be effective (in terms of bringing about more sustainable travel choices and/or assisting travellers) is likely to be determined by factors and issues associated with the quality of the information available (and by implication the underlying data) and the user requirements and behavioural responses.

\section{Moving towards integrated multi-modal information}

Aspirations and developments concerning the integration of information across modes and of the modes themselves is well documented. In the USA, the Advanced Public Transport Systems State-of-the-Art summary (Casey et al. 1998) acknowledges that many regional systems of information provision are becoming multi-modal, offering the travelling public an opportunity to make fully informed mode choice decisions about travelling in that locality.

In Europe, Kinnock (1996) emphasises the need for a Europe-wide 'Citizens' Network', the aim of which is to promote passenger transport services and information, including the effective integration of individual modes. More specifically, in France in early 1998, a road information press agency was formalised in order that information collected from the public transport bodies can, in the future, be circulated as widely as possible to users of the road network around Paris (DurandRaucher 1998). 
In the Netherlands, a single communication network infrastructure (VICnet) for use along the roadside is currently being designed and implemented (Van Houtert and de Ronde 1998). The Netherlands Ministry of Transport defines its task as 'the provision of reliable, up-to-date information to enable travellers both before and during their journeys to choose the time at which they will travel, and the route and transport mode they will take' (Van Toorenburg 1999). In Germany, the Integrated Mobility and Transport Network project (MTV) is designed to enable linking of existing and future transportation databases, in preparation for new mobility information services (Kersken and Hempel 1998).

In the UK, the Technology Foresight 'Progress Through Partnership’ Panel (1995) highlights the benefits to travellers, non-travellers, information suppliers, transport operators and local and national governments of an integrated transport information system. The Task Force on 'Transport Intermodality’ (1996) notes that 'key actors in the transport sector will have to transform their modal approach of today into a more integrated and holistic one to address the transport problems of tomorrow in an efficient manner'. In its 1998 Consultation Document, 'A Policy for using new telematic technologies for road transport', the Department of the Environment, Transport and the Regions (DETR) offers strong arguments for the Government to set national standards in terms of Urban Traffic Management and Control (UTMC) and in setting up Regional Traffic Control Centres (RTTCs) (DETR 1998a).

\subsection{Integrated information for public transport}

Comprehensive integration of information systems across travel modes demands that individual modes' information systems are sufficiently developed. In particular there is a need to have a public transport information system within which 
information from multiple operators and/or sub-modes is integrated. Substantial and ongoing recent developments have been taking place in the UK concerning provision of public transport information although these have been preceded by a number of impediments. It was previously noted that in a de-regulated transport environment (as is the case with the UK bus industry), competitive instincts run counter to the open sharing of information and the implementation of multi-mode travel information systems will be slow and piecemeal ('Progress Through Partnership’ Panel 1995). The much greater diversity of operator involved in the provision of public transport services in the UK has resulted in uncertainty for users and, hence, is a contributory factor towards a shift from public transport to the private car (Anderson et al. 1997). These separate companies have generally been unwilling to collaborate in the provision of comprehensive local timetable information (Slevin 1997). The task of compiling and disseminating such information has usually fallen on the relevant local authority.

In its 1998 White Paper the UK Government committed itself to the establishment of a National Public Transport Information System (NPTIS) by 2000. A similar service is already in use in the Netherlands, where public transport users can access the 'Public Transport Travel Planner', a national telephone enquiry service offering timetable, fare and other information, from a single telephone number (Van der Loop 1994).

Although a longer term aim of the NPTIS will be to include fares information, the initial aim is to provide timetable-based information. This will be made available in the first instance via a telephone enquiry service, although the Internet is explicitly acknowledged as an alternative delivery mechanism and one that is likely to assume a dominating role in the future (Thompson and Sheat 1998). 
The NPTIS requires the integration of information across different public transport modes (bus, coach, tram, train, ferry and underground/metro) and regions of the UK. The Government has not commissioned the production of the NPTIS since many local authorities and public transport operating companies already have the necessary data as a basis to contribute to such a system and a significant stake in delivery. The Government has seen partnership between different local authorities and public transport operators as a key to delivering the NPTIS (Lyons 1999a). Partnership and co-operation are particularly important given the limitations of current legislation. Local authorities currently only have a power to ensure bus passenger information provision in their area. The new Transport Bill in the UK is seeking to change this power to an obligation. A package of measures is being sought to promote stability of bus services and in turn information provision, for example by reducing frequent timetable changes. Bus operators are already under a legal obligation to register details of their local services but at present the format in which bus registration information is supplied varies widely. The Government therefore proposes to introduce a standard registration format and ideally an obligation to supply information electronically (DETR 1999c). Collectively these measures should foster greater co-operation and coordination in making comprehensive local bus information available as an input, subsequently, to the NPTIS.

Set against this political background, public transport information systems are advancing rapidly with a number of journey planning facilities available via the telephone or over the Internet (a comprehensive list of public transport information Web sites can be found at www.pti.org.uk). As Web sites continue to emerge and coverage increases it is likely that a user will eventually be able to plan a door-to-door long distance public transport trip using information from a series of different Web sites. However, for the user to do so 'manually' would be a time consuming and daunting task. 
Key players in the industry recognised this issue even before the NPTIS was conceived and saw the need for integration of information. The JourneyWeb project was subsequently awarded Government and industry funding to develop a means by which information from a series of local distributed databases could be combined to address Web-based enquiries covering more than one area, mode or operator (Fingerle et al. 1998). It is likely that a federal system such as this will now be adopted by the industry as a means by which, through the co-operation and interaction between a series of locally held and managed databases, a NPTIS can be delivered via the Web. Indeed it is expected that such as system will be used as the basis to provide a supporting role to operators in telephone enquiry bureaux.

\subsection{Highway network information}

The HA is pursuing a traffic control centre(s) (TCC) project under the Private Finance Initiative. Once established, the aim of the TCC is to dynamically control traffic on the trunk road network through strategic network management and by providing real time information to users either directly or through third party valueadded service providers (VASPS). A survey of potential information suppliers in the Traffic information And Navigation for GOthenburg (TANGO) project indicated that there was widespread interest in being part of the information infrastructure (Biding and Moutel 1994). Information will be made available via a computerised 'travel information highway' (TIH), from which all driver information service providers will be able to access relevant and reliable information to pass on to their customers (Hobbs et al. 1999). Motorists will receive information via a network of Variable Message Signs (VMS) and an Internet and Telephone public information service supported by the TIH. The TIH was originally the Traffic Information Highway, but this has changed to Travel, in recognition of the need for multi-modal, integrated 
information provision. The TIH offers one possible platform from which such provision could be developed and indeed this is the intention.

A demonstrator project of the TIH has already been developed. A near realtime database, Quantified Motorway Information Supply System (QMISS) holds dynamic information such as the current status of signals and signs on the motorway network, the current settings of text on VMS, speed limits set by automatic incident detection systems and signals set manually by the operator. Also within the database is static information about the locations of all the available devices on the motorway network. It is envisaged that later developments of QMISS will include vehicle speeds and flows to be held in the database, which will be accessible via the Internet. It is likely that such data will be stored and available for processing and analysis to aid in the long-term strategic policy decision making, much in the same way that local data collated by the ROMANSE Central Processor in the city of Southampton is used (Wren and Jones 1996).

\subsection{Issues to be addressed}

Traveller information is a topic that has received considerable attention from both the transport industry and research community. However it is only very recently that technological advances (in particular the Internet and other forms of networking) have presented a real possibility of collecting and integrating information across modes and in turn making such information accessible to a large proportion of the travelling public. Uni-modal and multi-submodal information systems are growing in number and quality. The technological opportunities coupled with a political will to manage travel demand now lead to the need to consider what issues must be addressed to determine whether and how to progress towards the provision of 
integrated driver and public transport information systems. It is suggested that the following issues require attention.

4.3.1. Who are the stakeholders in the provision of integrated information (and what are their roles)?

The principal user of integrated information systems will be the traveller or 'end-user'. Call-centre operators and VASPS will almost certainly become intermediate users. There may also be benefits to public transport services that are affected by highway travel times (reliability) in having highway information to improve management and (real-time) passenger information for their services. It is important to understand the benefits to public transport service providers, as their support will be necessary when implementing a system of integrated information provision (as noted by Holmes et al. (1994) in relation to the development on an integrated public transport system in the city of Birmingham as part of the QUARTET project). The HA and the public transport service providers are both likely to experience changes in the use of their networks if integrated information is available. It will be necessary to consider what commitments from these stakeholders are likely or should be expected.

Commitments will include a need for investment in capital and running costs, exchange of information in compatible formats and probably partnership agreements. One such agreement was established prior to the launch of the White Paper. The HA and Railtrack (the owner and operator of the national rail infrastructure) signed a memorandum of understanding with an agreement to work together to implement plans to better integrate the strategic road network with the rail network (HA 1998). The degree of commitment, particularly given the absence of legal obligation, will be influenced by perceived benefits to each stakeholder. Benefits relate to changes in the 
levels or distributions of travel demand. An understanding of end-user requirements from, and reactions to, integrated information provision will therefore be crucial.

There is a need to consult stakeholders. There are several examples in the UK of activities concerned with bringing together stakeholders to address the issues of (integrated) traveller information provision. The HA, in association with CIRIA, has been piloting a learning network. The 'Integrated Transport Operators Network' (ITON) aims to 'bring together diverse stakeholders to exchange and disseminate knowledge, to build relationships through discussion, to benchmark activities and to create a climate for action' (CIRIA 1999). At its third workshop, the issue of traveller information across modes was considered (Lyons 1999b). A consortium of public and private organisations with a vested interest in traveller information has been coordinated by CEST with research support from the University of Southampton (Board et al. 1999).

4.3.2. What types of information are of specific relevance to an integrated information system?

Although certain aspects of information such as journey time will be a common expectation from either a public transport or highway information system, in other respects the potential information that is provided for each mode of travel may be very different. For example, while a timetable is an immediately obvious information option for public transport it would be inappropriate for private transport. It is important to understand what information is required to plan and complete a journey by public transport (or other mode combinations to the private car) and the equivalent understanding is required for a journey by car. The next step is to investigate how these two sets of information requirements might interact in the context of assembling and presenting integrated information that enables comparison of travel factors across modes. 
4.3.3. How should driver information be integrated with other modes' information systems?

This is not an issue concerning technological requirement but primarily one of defining user reactions. It is necessary to ensure, as stated earlier, that integration occurs in a form that is not only comprehensive but comprehendable for end-users thereby enabling them to make effective use of the information provided. The degree to which comparable information across modes needs to be integrated within information systems to be effective will vary amongst travellers. A traveller with limited ability or inclination to assemble and interpret relevant information is likely to require more integration of information than a traveller capable of and willing to visit a different information source for each mode (which may each present information in different ways) and assemble and compare information across modes. With currently available web sites, the latter is already a viable option in some cases (Lyons 1999a). The way in, and extent to which, information is integrated will also need to take account of the point at which information is required or accessed. Although mobile communications devices make en-route mode choice decisions a possibility, it is likely that in most cases the need for integrated information systems will exist at the pre-trip stage.

4.3.4. What is the current and future scale of access to and demand for (integrated) information?

Ongoing technological developments present increasingly sophisticated and flexible information delivery mechanisms. Current and forthcoming technological developments need to be identified, as well as determining when they will become available to the (mass) market. In turn, it is important to assess the demand for information that will prevail as access to information becomes increasingly affordable and more widespread. 
4.3.5. What will the nature and scale of the resulting (dis)benefits of integrated information be (and how will these change over time)?

Traveller information is a potentially powerful means of travel demand management. The implicit assumption that the provision of integrated information is a positive thing for a given stakeholder should be questioned. The principles of traveller information systems and their potential influence on travel choices are generally well understood. However, the actual consequences of information provision particularly in the selection of travel options that are available in practise do not appear to have been clearly established. The scale of benefits (or disbenefits) of integrated information delivery is unclear.

Without this insight, it is difficult to assess the effects of integrated information provision and more particularly the scale of those effects on the highway network and public transport services across the entire population's travel on a daily basis. It is suggested that research should consider a cross-section of real-trips made using the highway network. For each trip, details about how the trip would be made using the highway network and/or alternative modes could be collected. This would determine for what proportion of car trips viable/competing (in terms of the various components of generalised travel cost) public transport-based alternatives exist. In cases where alternatives do not exist information provision on such alternatives will be unlikely to have any impact.

It is also necessary to acquire reliable insights into how travellers and particularly drivers will respond in practise to the provision of integrated information. Previous research investigating traveller information systems has used statedpreference techniques to assess travellers' reactions. (See for example, Bonsall et al. 1991, Polak and Jones 1993, Beaton and Sadana 1995, Papaioannou et al. 1996) Such techniques can have significant shortcomings in terms of the validity of 
participants' responses to hypothetical situations with which they are presented. This problem would prevail if such techniques were used (solely) to investigate the new concept (from the users’ perspective) of integrated information.

A suggested alternative approach to this issue is a study involving real-life intervention. Drivers' requirements from, and reactions to, integrated information in the context of actual trips being planned/executed could be investigated. For a small sample of drivers, an integrated information broker service could be provided to emulate what a future integrated information system might offer. Drivers would inform the service in advance of trips to be made. Detailed information specific to each trip across possible mode options would then be gathered manually by the service and compiled into an integrated information summary that would then be returned to the driver concerned. The novel concept of a personal timetable and planning information service would be welcomed by a majority of travellers (Vance and Balcombe 1997). The sample would then subsequently be required to provide reactions to and comment on the information provided and the influence it had on the actual trip decision(s). Such a study could provide detailed and invaluable insights into how and what integrated information should be provided and the consequence of its provision.

\section{Conclusions}

Technology has brought about the permeation of an information culture into society. Hitherto the likelihood of information required by an individual being available, coupled with the individual having a means to conveniently and easily access that information, was comparatively small. The Internet in particular now offers a seemingly unbounded information resource on virtually any topic. There is a growing public realisation of this and in turn an increasing expectation and inclination 
to find information including that related to travel. Technology is accelerating the opportunities to deliver traveller information to the public and the current political will (certainly in the UK) is to seize these opportunities. A highly desirable opportunity is that to develop integrated multi-modal information systems enabling convenient and direct comparison of travel cost factors across alternative modes. There are clear expectations that multi-modal information can influence mode choice and more specifically a presumption by some that the (only) influence will be a change from travelling by car to public transport. There is an urgent need for better understanding of the consequences in practise of providing integrated traveller information systems. Such systems must be seen as complimentary to rather than substituting for improvements to public transport services if car dependence is to be tackled effectively. The effective delivery of integrated information relies upon a number of key issues highlighted in this paper. Not surprisingly research needs principally concern the end-user. It is important that such needs are addressed in parallel to technological developments as the evolutionary progress of information provision continues.

\section{Acknowledgements}

The views expressed in this paper are those of the author and do not necessarily reflect those of the Highways Agency. Nevertheless the author wishes to acknowledge the support of the Highways Agency that will enable research in this field to be progressed. 


\section{References}

Anderson, N., Andrews, D. and Brader, C., 1997, Public transport information on the Internet. Proceedings 4th World Congress on Intelligent Transport Systems, Berlin, 21-24 October.

Association of Train Operating Companies, 1999, ATOC Bulletin. November.

Austin, J., 1999, Towards comprehensive national public transport information on the Internet: the PTI website. Proceedings of the European Transport Conference, Public Transport Planning and Management, Cambridge, 2729 September, PTRC, pp. 151-163.

Automobile Association, 1997, Living with the car. AA Policy.

Beaton, P. and Sadana, A.,1995 Demand for a pre-trip ATIS conditioned upon communications media: a stated choice analysis. Proceedings of the 1995 Annual Meeting of ITS America, 1, pp. 253-263.

BIDING, T. and MoutAL, V., 1994, Route guidance and dynamic traffic information: a same goal but different contexts. Proceedings of the 1st World Congress on Applications of Transport Telematics and intelligent Vehicle-Highway Systems, Paris, December, 5, pp. 2737-2734.

Board, P., Greaves, C. and Amorelli, T., 1999, Informing the traveller. Traffic Technology International, June/July 1999, pp. 96-99.

Casey, R., Labell, L., Carpenter, E., LoVecchio, J., Moniz, L., OW, R., Royal, J., SCHWENK, J. and SCHWEIGER, C., 1998, Advanced public transportation systems: the state of the art. US Department of Transportation, Federal Transit Administration, Update.

CIRIA, 1999, The essential agenda. Workshop Report, Integrated Transport Operators Network. 
DETR, 1998a, A New Deal for Transport: Better for Everyone. Transport White Paper, TSO, London.

DETR, 1998b, A Policy for Using New Telematic Technologies for Road Transport. Consultation Document.

DETR, 1999, Transport Statistics Great Britain 1999 Edition. Government Statistical Service, TSO.

DETR, 1999b, The Key to Easier Home Buying and Selling - Technical Issues. http://www.housing.detr.gov.uk/hbs/tech/8.htm (last viewed 26/01/00).

DETR, 1999c, From workhorse to thoroughbred - a better role for bus travel. TSO, London.

DOT, 1996, Transport: The Way Forward. Transport Green Paper, HMSO.

DURAND-RAUCHER, Y., 1998, The ability of individuals to adjust their travel behaviour: examples of public response today and in the future. Proceedings of the 5th World Congress on Intelligent Transport Systems, Seoul, Korea, 1216 October.

Fingerle, G., Lock, T. and Slevin, R., 1998, JourneyWeb: a protocol for a distributed public transport journey planner. Proceedings of the European Transport Conference, Public Transport Planning and Operations, Loughborough University, 14-18 September, PTRC, pp. 145-154-101.

GiLlam, T., Lyons, G.D. and McDonald, M., 1999, Traveller information systems: what do end-users really want?. Proceedings of the European Transport Conference, Traffic Management, Safety \& Intelligent Transport Systems, Cambridge, 27-29 September, PTRC, pp. 329-341.

Harris, P. and Konheim, C., 1995, Public interest in, and willingness to pay for, enhanced traveler information as provided by IVHS in the New York 
Metropolitan Area. Proceedings of the Annual Meeting of ITS America, 1, pp. 247-251.

HA, 1998, Highways Agency and Railtrack sign Partnership Agreement. Highways Agency News Release HA/267, 20 July.

Hobbs, A., Yearworth, M. and Still, P., 1999, Traffic Information Highway. Driver information systems: influencing your route, seminar, IEE.

Holmes, K., Blackledge, D., Foti, G., Meier, W., Pickup, L. and Psaraki, V., 1994, The development of integrated public transport passenger information systems in the QUARTET Project. Proceedings of the 1st World Congress on Applications of Transport Telematics and Intelligent Vehicle-Highways Systems, Paris, 30 November - 3 December, 6, pp. 2912-2919.

IHT, 1997, Transport in the Urban Environment. The Institution of Highways and Transportation, London.

INTERNET MAGAZINE, 1999, Trendspotting. Internet Magazine, Dec.

KersKen, U. and Hempel, K., 1998, MTV - integrated mobility and transport network. Proceedings of the 5th World Congress on Intelligent Transport Systems, Seoul, Korea, 12-16 October.

KinNOCK, N., 1996, The Citizens’ Network. European Commission Green Paper.

LyONS, G.D., McDonald, M. and Bunford, J., 1998, Internet traveller information systems: a case study of user response. Proceedings of the $8^{\text {th }}$ World Conference on Transport Research, Antwerp, Belgium, 12-17 July.

LYONS, G.D., 1999a, Behavioural patterns: making informed choices. Paper presented at Integrated Transport Operators Network Workshop, July, CIRIA.

LYONS, G.D., 1999, UK passenger transport information on the Internet: promoting best practice through accreditation. Proceedings of the European Transport 
Conference, Public Transport Planning and Management, Cambridge, 2729 September, PTRC, pp. 127-138.

MCINTOSH, 2000, Handset sales near 50,000 a day as mobile phone fever grips UK. The Independent, Business Section, 6 January, p. 16.

NeTWORK WIZARDS, 1999, Internet Domain Survey. http://www.nw.com/ zone/WWW, (last viewed 14/06/99).

OJALA, T., 1999, Traveller and traffic information service for mobile individuals, Proceedings ITS in Europe '99 Congress.

OrtúZar, J. De D. and Willumsen, L.G., 1994, Trip Distribution Modelling. In: Modelling Transport, Wiley.

Papaionnnou, P., Basbas, S. and Vougioukas, M., 1996, The use of stated preference technique in evaluating a passenger information system: the EUROBUS/ POPINS/THEPIS experience. Proceedings of the European Transport Forum, Public Transport Planning and Operations, 2-6 September, PTRC.

PolAK, J. and JonES, P., 1993, The acquisition of pre-trip information: a stated preference approach. Transportation, 20(2), pp. 179-98

Polydoropoulou, A., Ben-Akiva, M. and Kaysi, I., 1994, Influence of traffic information on drivers' route choice behavior. Transportation Research Record, 1453.

Progress Through Partnership PANel, 1995, The Informed Traveller. Technology Foresight.

SACTRA, 1994), Trunk roads and the generation of traffic. HMSO.

SLEVIN, R., 1997, Presenting local travel information on the World Wide Web: Buckinghamshire and beyond, Proceedings of the European Transport Forum, 
Public Transport Planning and Operations, 1-5 September, PTRC, pp. 195206.

TASK Force 'Transport Intermodality', 1996, Identifying the Main Policy, Business, Technical and Social Issues Underlying the Evolution of Intermodal Transport, Diagnosis Report, CORDIS.

Thompson, S. and SheAt, D., 1998, Exploiting telecommunications to deliver real time transport information, Proceedings of the 9th International Conference on Road Transport Information and Control, April, Institution of Electrical Engineers, London, pp. 59-63.

VAN Der LoOP, J., Kroes, E., HofKer, H. and Bronner, A.,1994, A new service for travel information about public transport in the Netherlands: initial effects and analysis of the market. Proceedings of the European Transport Forum, Public Transport Planning and Operations, 12-16 September, PTRC, pp. 73-81.

VAN HOUTERT, M. and DE RONDE, F., 1998, VICnet: a nation-wide digital highway for traffic and transportation applications. Proceedings of the 5th World Congress on Intelligent Transport Systems, Seoul, Korea, 12-16 October.

Van Toorenburg, G., 1999, Multimodal traveller information. Proceedings of the ITS in Europe Congress.

VAnCE, C. and BALCOMBE, R., 1997, How to tell bus passengers what they need to know. Proceedings of the European Transport Forum, Public Transport Planning and Operations, 1-5 September, PTRC, pp. 231-42.

Wren, A. and Jones, P., 1996, ROMANSE - Road Management System for Europe. Proceedings of the 8th International Conference on Road Traffic Monitoring and Control, April, Institution of Electrical Engineers, London, pp. 23-27. 


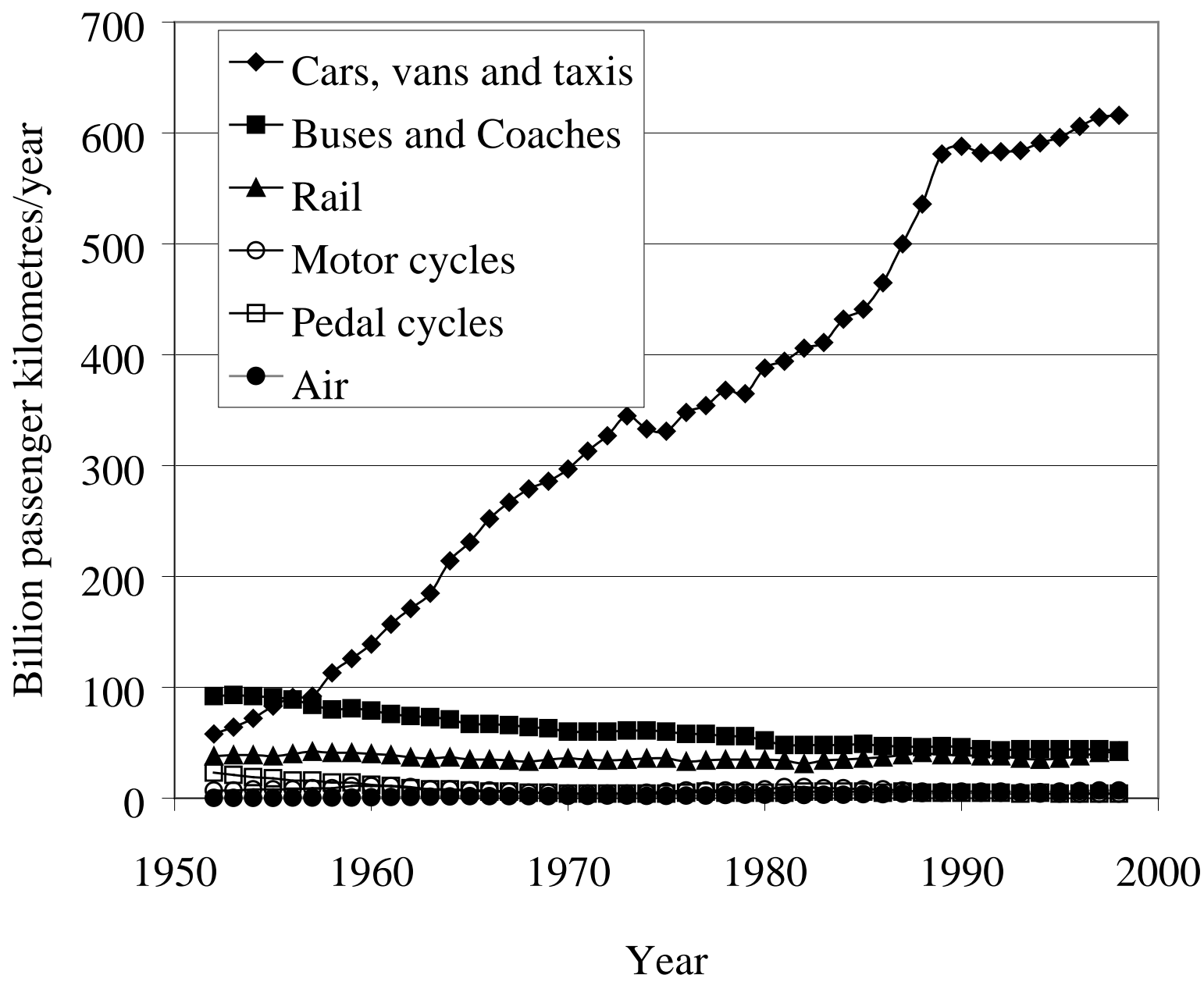

Figure 1. Billion passenger kilometres/year traveled in the UK per year by mode: 1952 - 1998 (source: DETR (1999a)). 
By 2010 over three quarters of homes in the UK will have access to the Internet and the vast majority of individuals will carry mobile phones. There will be a proliferation of increasingly high quality and information rich Web sites coupled with effective searching techniques. Public expectation to be able to access information on almost any topic including travel will be high. Continued traffic growth will place increasing pressure on highway network capacity. Economic instruments penalising car use and a noticeable improvement in public transport systems particularly for inter-urban travel will have generated a growth in demand from travellers and especially car drivers for information about travel options. Advances in telecommunications will have enabled extensive data gathering infrastructure to be established. The coverage of the transport networks and the quality of data, will have begun to attract a significant number of value-added service providers into the industry of traveller information provision. Traveller information systems will have national coverage and integration of systems will offer time-based comparison of travel options across modes. Individual modes' information systems will offer more detailed information covering other travel factors such as monetary cost and reliability. Information systems will familiarise travellers, and in particular drivers, with the travel options available for given trips. This will lead to mode switching for a limited but significant number of trips.

By 2030, the sophistication and affordability of technology will make access to traveller information possible for all or most people irrespective of time or location. For a growing proportion of trips made, it will be commonplace for travellers to review their travel options using information systems. Travellers will expect information to be quick and easy to access and specific to their needs. Data and data management techniques will be available to support fully integrated multi-modal information systems that provide information addressing a number of travel factors beyond only time and monetary cost. Subscription or pay-per-use systems will exist alongside nonchargeable systems. The former will offer a much higher degree of personalisation and timely delivery. The quality and reliability of public transport systems will have improved considerably and information systems will play a part in making journeys using such systems appear more seamless and convenient. Integrated information systems will perform a key role in achieving a more balanced distribution of demand across modes.

Figure 2. A vision of the future. 


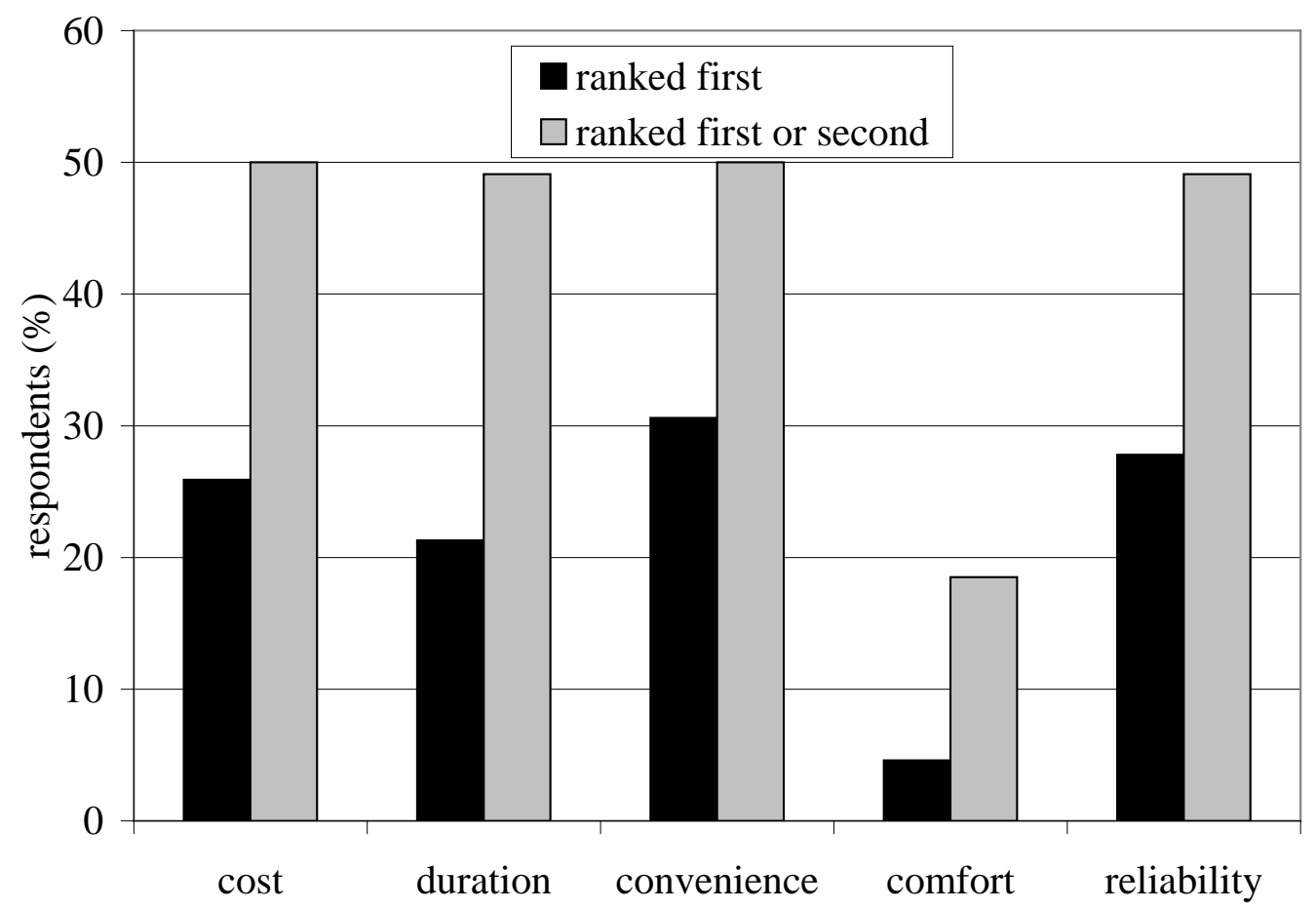

Figure 3. Ranking of travel factors' importance (Lyons et al. 1998). 


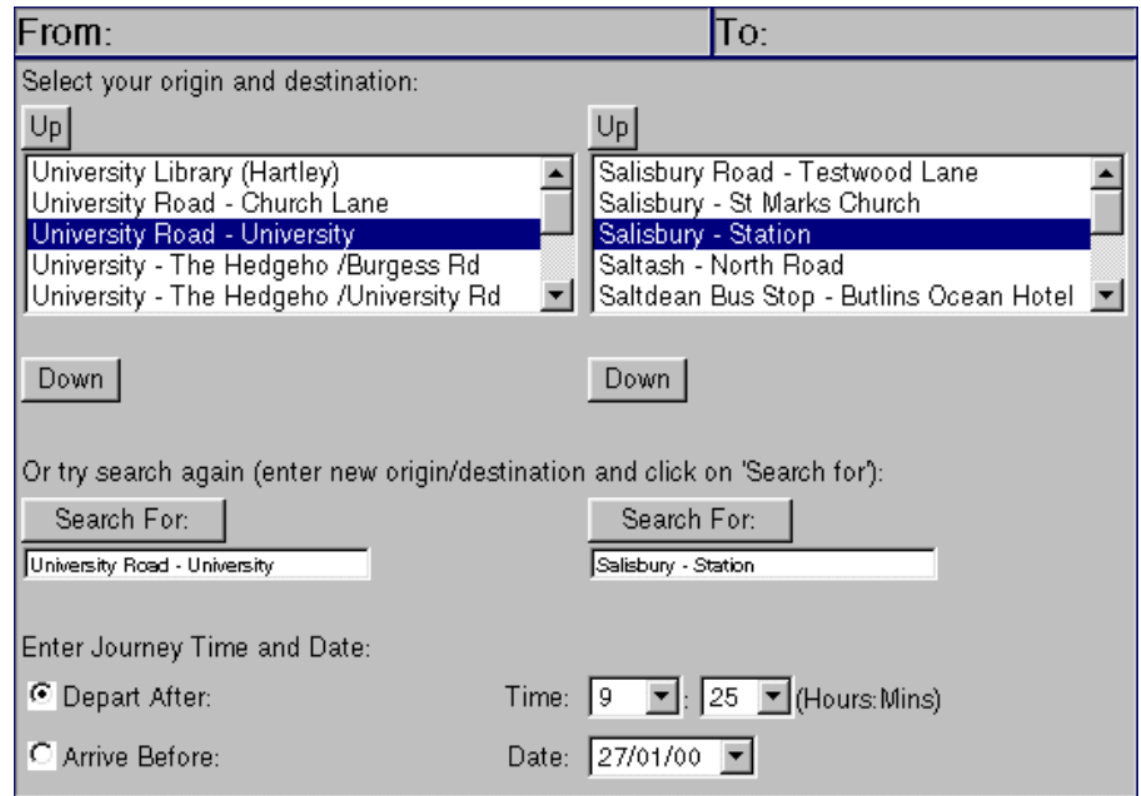

\section{Public transport routes available}

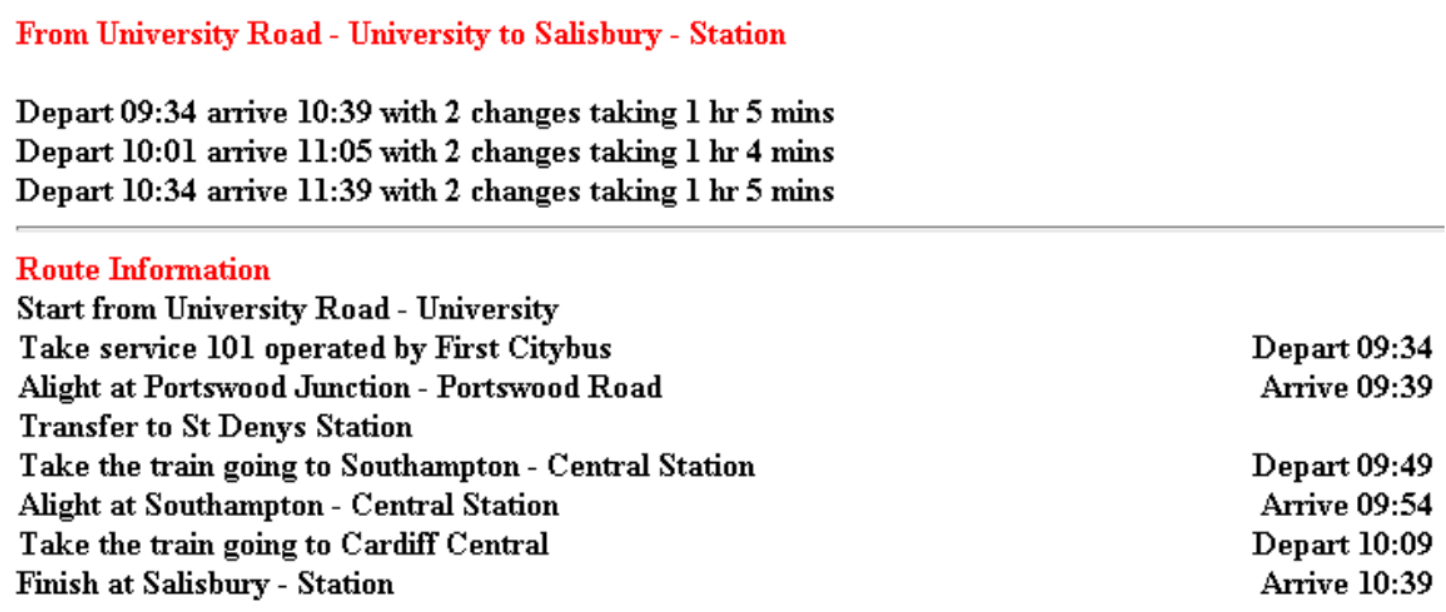

Figure 4. A typical journey planner enquiry interface and response screen (see http://www.romanse.org.uk/). 


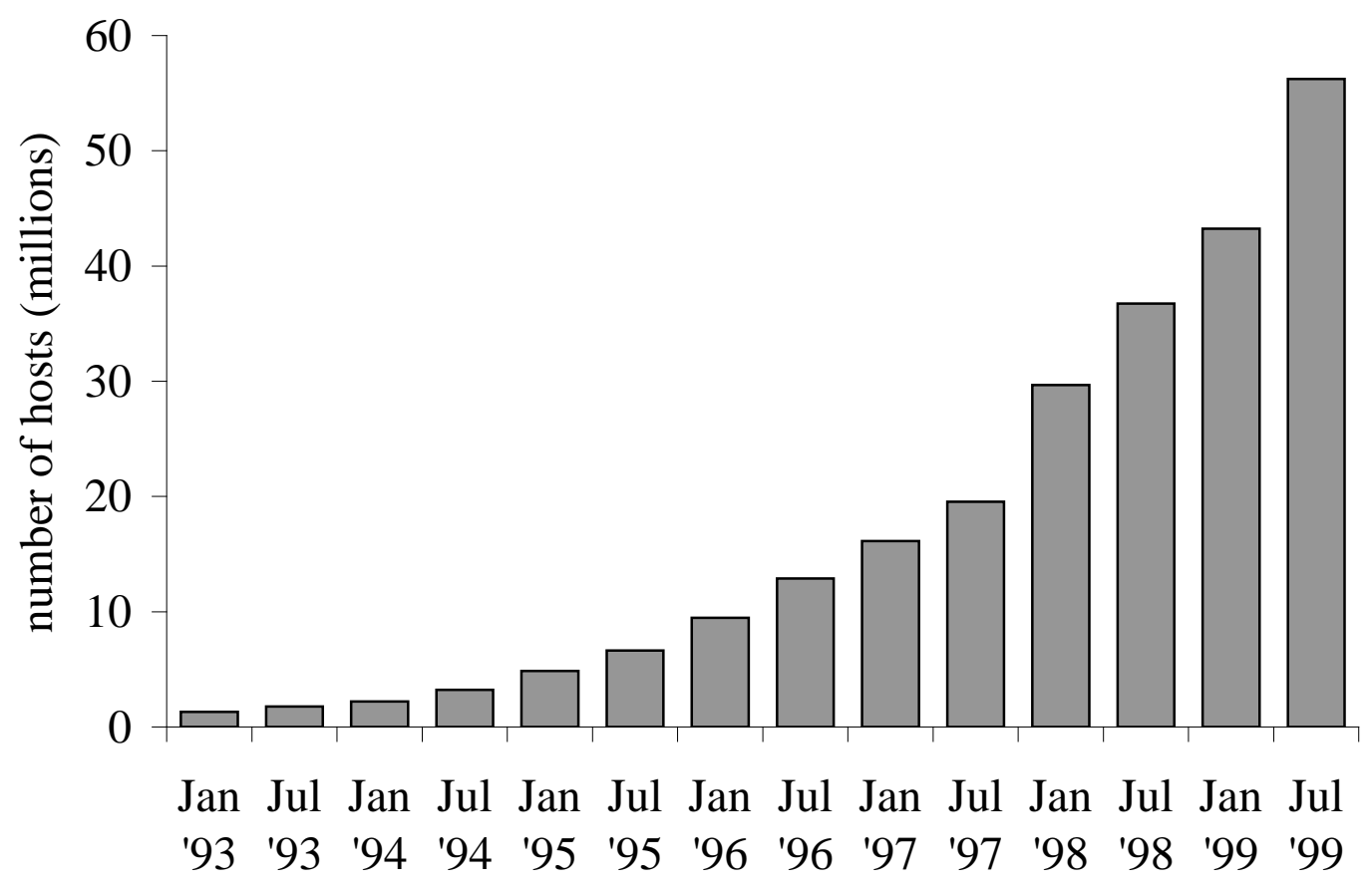

Figure 5. Growth in Internet use (source: Network Wizards (1999)). 


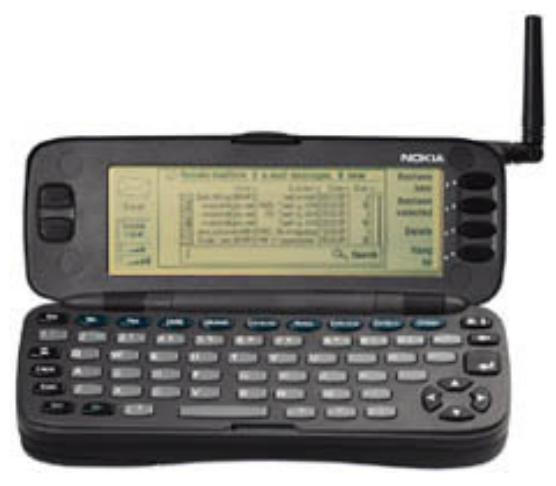

Figure 6. An example of a Personal Digital Assistant - the Nokia Communicator (see http://www.nokiausa.com/). 
Table 1. Reasons quoted for not using public transport and instead using the car (source: AA (1997)).

\begin{tabular}{lc}
\hline \multicolumn{1}{c}{ Reason } & $\begin{array}{c}\text { Proportion of } \\
\text { respondents }\end{array}$ \\
\hline Inconvenient & $56 \%$ \\
No suitable service & $42 \%$ \\
Takes too long & $39 \%$ \\
Too expensive & $35 \%$ \\
Unreliable & $35 \%$ \\
Have to wait & $35 \%$ \\
Dirty & $22 \%$ \\
Overcrowded & $10 \%$ \\
\hline
\end{tabular}

